\title{
Patterns of digital device usage and its related health effects on elementary and middle school students: an instrument development and regression analysis
}

\author{
Abdullah Ahmed Alamri ${ }^{1}$, Nizar Alhibshi ${ }^{2}$, Majed Alnefaie ${ }^{1}$, Wejdan Alzhrani ${ }^{3}$, Adel Almaymuni ${ }^{1}$, Mahmoud \\ Mosli $^{4}$
}

${ }^{1}$ Faculty of Medicine, King Abdulaziz University, Jeddah, Saudi Arabia

${ }^{2}$ Consultant, Department of Ophthalmology, Faculty of Medicine, King Abdulaziz University, Jeddah, Saudi Arabia

${ }^{3}$ Faculty of Medicine, Um Al-Qura University, Jeddah, Saudi Arabia

${ }^{4}$ Consultant, Department of Internal Medicine, Faculty of Medicine, King Abdulaziz University, Jeddah, Saudi Arabia

\section{Type of article: Original}

\begin{abstract}
Background: The use of digital devices has increased tremendously during recent years in Saudi Arabia. Many concerns were raised about the safety of this technology.

Objective: To develop an instrument for determining the pattern of use of digital devices, and to investigate the link between the use of digital devices and visual symptoms among students of general education schools.

Methods: This cross-sectional study was carried out from the beginning of April 2017 to the end of September 2017 among students of general education schools in the Western region of Saudi Arabia. The study sample included 475 randomly selected participants. A self-administered questionnaire was used for data collection. The questionnaire had two parts: the first part was about personal information of the study participants, while the second part was about the pattern of use of digital devices, associated visual complaints after use, and recommendations to decrease visual health hazards. IBM-SPSS version 22 was used to conduct the statistical analysis. Logistic regression analysis was used to examine associations with visual and muscular complaints; odds ratios with $95 \%$ confidence intervals were generated. Chi square goodness-of-fit test was used to compare categorical variable frequencies across different groups. A p-value of $<0.05$ was considered statistically significant.

Results: A total of 475 students completed the questionnaire. Nearly half the respondents were males aged more than 19 years old $(\mathrm{p}<0.001)$. Most respondents attended secondary schools $(\mathrm{p}<0.001)$. Most users experienced neck or shoulder pain $(n=305,64.2 \%, p<0.001)$, followed by headaches $(n=301,63.4 \%, p<0.001)$, and visual disturbances $(n=275,57.9 \%, p=0.001)$. The majority of students used cellular phones or tablets $(n=389,83.8 \%)$. Half the respondents spent more than 4 hours daily using digital devices $(\mathrm{p}<0.001)$ and had 2 or more devices. Most students agreed that decreasing the duration of usage $(\mathrm{n}=217,45.7 \%)$ and scheduling hours $(\mathrm{n}=214,45.1 \%)$ are the best solutions to decrease the health hazards of digital devices. Logistic regression analysis identified female gender (OR: 2.8, 95\% CI: 1.6-4.8, $\mathrm{p}<0.001$ ) and exposure to digital devices for more than 2 hours per day (OR: $2.9,95 \%$ CI: $1.4-6.3, \mathrm{p}=0.006$ ) as significant predictors of symptoms.

Conclusion: A significant proportion of school students were aware that prolonged use of digital devices is associated with visual and muscular complaints. Females and individuals spending more than 2 hours a day using these devices are more prone to visual and muscular complaints. Decreasing the hours of usage is necessary to avoid digital device-related health risks.
\end{abstract}

Keywords: Cellular Phone; Computer; Eyestrain; Syndrome; User-Computer Interface; Vision

\section{Corresponding author:}

Faculty of Medicine, King Abdulaziz University, Jeddah, Saudi Arabia.

Tel: +966.544442173, Email: dr.abdullah125@gmail.com

Received: July 29, 2018, Accepted: October 09, 2018, Published: November 2018

iThenticate screening: October 11, 2018, English editing: October 23, 2018, Quality control: October 26, 2018

This article has been reviewed / commented by three experts

Ethics approval: King Abdulaziz University (Ref: 221-18; date of approval: March 10, 2017)

(C) 2018 The Authors. This is an open access article under the terms of the Creative Commons Attribution-NonCommercialNoDerivs License, which permits use and distribution in any medium, provided the original work is properly cited, the use is non-commercial and no modifications or adaptations are made. 


\section{Introduction}

The use of digital devices, such as televisions (TV), microwaves, computers, and smart phones, has increased in recent decades as they have entered into the routine of everyday life. People of all ages, sex, race, and education are using digital devices for work, education, communication with others, and for entertainment (1). The increase of different kinds of Social Networking Sites (SNSs) at regional and international level has impacted significantly the time spent using digital devices (2). Communication via these networks is growing increasingly among students (3, 4). Several studies have highlighted the health hazards of prolonged usage of these devices. The reported symptoms by users of these devices include lacrimation, blurred vision, and warmth on the ear and behind/around the ear (5-7). Other health hazards include social isolation, nutritional disorders, depression (5, 7-9), deterioration of academic performance and addiction-like phenomenon (10-12), as well as a potential role in induction of tumors (13). Digital devices can affect health through multiple mechanisms. Brightness of the device screen can affect the eye, particularly at night, whereas emission of radiation may affect the brain, nerves, eyes, and ears (14).

Digital devices are widely used among the population of Saudi Arabia (1). However, only a few studies have been conducted to assess health problems related to their overuse. Meo and Drees (6) evaluated visual and hearing complaints in adults in Riyadh. However, this problem was not adequately studied in children and adolescents. Therefore, this study aimed to describe the pattern of use of digital devices, and to investigate the link between the use of digital devices and visual symptoms among students of general education schools in the Western region of Saudi Arabia. The general objective of this research was to describe the pattern of use of digital devices. The specific objectives were: 1) to determine the link between the use of digital devices and visual symptoms among students of general education schools in the Western region of Saudi Arabia, and 2) to identify the predictors of visual and muscular symptoms.

\section{Material and Methods}

\subsection{Study design}

This study had a cross-sectional design. It was carried out from the beginning of April 2017 to the end of September 2017 among students of general education schools in the Western region of Saudi Arabia.

\subsection{Study population and sample size}

A sample size of 475 participants (both male and female students), more than 6 years-old were randomly recruited from Elementary, Intermediate and Secondary Schools in the Western region (Jeddah, Taif, Makkah), Saudi Arabia. The sample size was calculated from the Cochran formula (15) as follows:

$\mathrm{n}=\left[\mathrm{Z}^{2} \mathrm{P}(1-\mathrm{P})\right] / \mathrm{d}^{2}$

Where:

Z: value from standard normal distribution corresponding to desired confidence level;

P: the expected proportion in population based on previous studies;

$\mathrm{d}$ : the degree of freedom.

\subsection{Sampling method}

Students were randomly selected (through simple random sampling) for participation in the study. Every student had equal probability of being chosen, we randomly chose 4 students out of 20 students in the every classroom, and in each school we did the same while taking into consideration our exclusion criteria

\subsection{Selection criteria and reducing potential bias}

\subsubsection{Inclusion criteria}

The inclusion criteria were students who were more than 6 years old and attending Elementary, Intermediate and Secondary Schools in the Western region (Jeddah, Taif, Makkah), Saudi Arabia.

\subsubsection{Exclusion criteria}

Students who suffered from visual or musculoskeletal symptoms that were attributed to a specific neurological or musculoskeletal disease or trauma were excluded at the beginning of the study (i.e. at the time of screening) to reduce the risk of confounding bias. Students who provided incomplete questionnaires were included, but were later excluded from the final analysis and considered as missing data.

\subsection{Instrument, validity and reliability}

A self-administered two-part questionnaire was used for data collection. The first part was about socio-demographic characteristics of the participants. The second part included three dimensions: 1) the pattern of use of digital devices 
(type, number, and duration of use), 2) associated visual complaints after use, and 3) recommendations to decrease visual health hazards. Regarding the validity and reliability of the instrument, the questionnaire was presented to two local expert rheumatologists for face validity and was tested on 10 volunteers two times, 2 weeks apart before the study was initiated. Intra and inter rater agreement was measured in the sub group using Kappa's and were deemed adequate.

\subsection{Data collection}

The questionnaire was distributed to the participants through direct contact. Data were confirmed then coded and entered into a personal computer. Thanks and appreciations were used to encourage participants' involvement in the study. Digital devices were explained to the participants and were defined as any devices that used electronic systems similar to computers. They included all devices with visual user interface, such as computers, laptops, cellular phones, tablets, and televisions.

\subsection{Statistical Analysis}

Data analysis was carried out using IBM( SPSS $\subset$ Statistics version 22 (IBMC Corp., Armonk, NY, USA). All variables were recorded in the datasheet as categorical variables. The results were tabulated and reported as frequencies and percentages for categorical variables. Bar charts were used to visually present some variables. Chi square goodness-of-fit test was used to compare frequencies of categorical variables across multiple groups. Stepwise forward binary logistic regression analysis was used to examine the relationship between duration of exposure and presence of visual and muscular symptoms, after adjusting for age and gender. Odds ratios (OR) were used to express associations with a significance threshold of $5 \%$ and $95 \%$ confidence. A p-value of $<0.05$ was considered statistically significant.

\subsection{Ethical considerations}

Declaration of Helsinki - ethical principles for medical research involving human subjects (adopted by the 18th General Assembly of World Medical Association [WMA], Helsinki, Finland, June 1964, and last amended by the 64th WMA General Assembly, Fortaleza, Brazil, October 2013) was considered throughout the designing of the study protocol and its implementation. This study was approved by the institutional review board of the Faculty of Medicine, King Abdulaziz University (Ref: 221-18; date of approval: March 10, 2017). Ethical approval was also obtained from all the schools' principals. Written informed consent was obtained from all participants. Maintaining confidentiality of the study participants was ascertained by making code numbers (available to investigators only) for each participant.

\section{Results}

\subsection{Baseline characteristics and general findings}

In this study, 475 students completed the questionnaire. Approximately half the respondents were males, with no statistically significant difference $(\mathrm{p}=0.714)$. A significantly higher percentage of respondents came from age groups "16-19 years" $(n=114,24 \%)$ and "above 19 years" $(n=247,52 \%)$. A significantly large proportion $(n=308,64.8 \%$, $\mathrm{p}<0.001)$ of the respondents attended secondary schools. Children aged 6 to 11 years old included 59 (12.4\%) participants (Table 1).

Table 1. Socio-demographic data of the study participants $(n=475)$.

\begin{tabular}{|l|l|l|l|l|}
\hline Variables & $\mathrm{n}$ & $\%$ & $\mathrm{p}$-value \\
\hline Age (year) & $6-11$ & 59 & 12.4 & \multirow{2}{*}{$<0.001^{*}$} \\
\cline { 2 - 4 } & $12-15$ & 55 & 11.6 & \\
\cline { 2 - 4 } & $16-19$ & 114 & 24.0 & \\
\cline { 2 - 4 } & $>19$ & 247 & 52.0 & \\
\hline \multirow{2}{*}{ Sex } & Male & 242 & 50.9 & \multirow{2}{*}{0.714} \\
\cline { 2 - 4 } & Female & 233 & 49.1 & \\
\hline \multirow{3}{*}{ Education } & Primary & 90 & 18.9 & \multirow{2}{*}{$<0.001^{*}$} \\
\cline { 2 - 4 } & Intermediate & 77 & 16.2 & \\
\cline { 2 - 4 } & Secondary & 308 & 64.8 & \\
\hline
\end{tabular}

*Significant at $\mathrm{p} \leq 0.05$.

A significantly lower percentage of respondents wore eyeglasses/lenses or had eye complaints $(n=200,42.1 \%$, $\mathrm{p}=0.001$ ). Neck or shoulder pain, following the use of digital devices, and headache were reported by significantly 
high percentages of respondents $(n=305,64.2 \%, p<0.001$ and $n=301,63.4 \%, p<0.001$ respectively), whereas eye dryness affected $248(52.2 \%)$ of respondents with no statistically significant difference $(\mathrm{p}=0.359)(\mathrm{Table} 2)$. The study showed that the majority $(83.8 \%)$ of respondents used cellular phones or tablets. Nearly one fifth of the respondents played electronic games (mainly play station and $\mathrm{X}$ box). The percentage of respondents using TV or computers/laptops was much lower (17.1 and 16.4\% respectively). Approximately one third of the respondents $(\mathrm{n}=163,34.3 \%)$ were used to spending $2-4$ hours on digital devices, while $49.9 \%$ spent much longer durations $(\mathrm{n}=129,27.2 \%$ for $4-6$ hours and $\mathrm{n}=108,22.7 \%$ for more than 6 hours, $\mathrm{p}<0.001)$. A higher frequency used more than one device $(n=169,35.6 \%$ had 2 devices and $n=102,21.5 \%$ had more than 2$)$. As regards the ill effects of using digital devices for long periods, most $(286,60.2 \%)$ of the respondents reported decreased visual acuity; a much lower percentage mentioned lack of concentration $(n=94,19.8 \%)$ and decreased academic performance $(n=57$, $12 \%)$, with significant difference $(\mathrm{p}<0.001)$. Most of the students agreed that decreasing the duration of usage $(\mathrm{n}=217,45.7 \%, \mathrm{p}<0.001)$ and scheduling hours $(\mathrm{n}=214,45.1 \%, \mathrm{p}=0.035)$ are the best solutions to decrease the $\mathrm{ill}$ effects of digital devices (Table 3).

Table 2. Visual and musculoskeletal complaints of the study participants $(n=475)$.

\begin{tabular}{|l|l|l|l|l|}
\hline Questionnaire items & $\mathrm{n}$ & $\%$ & $\mathrm{p}$-value \\
\hline Do you wear eyeglasses/lenses or have eye problems? & No & 275 & 57.9 & \multirow{2}{*}{$0.001^{*}$} \\
\cline { 2 - 5 } & Yes & 200 & 42.1 & \\
\hline Do you have neck/shoulder pain when using digital devices? & No & 170 & 35.8 & $<0.001^{*}$ \\
\cline { 2 - 5 } & Yes & 305 & 64.2 & \\
\hline Do you have headache after using digital devices for long periods? & No & 174 & 36.6 & \multirow{2}{*}{$<0.001^{*}$} \\
\cline { 2 - 5 } & Yes & 301 & 63.4 & \multirow{2}{*}{0.359} \\
\hline Do you have eye dryness after using digital devices? & No & 227 & 47.8 \\
\hline
\end{tabular}

*Significant at $\mathrm{p} \leq 0.05$.

Table 3. Duration and number of digital devices, their condition and suggested solutions.

\begin{tabular}{|c|c|c|c|c|c|}
\hline Questionnaire items & Total & \multicolumn{2}{|l|}{$\mathrm{n}$} & $\%$ & p-value \\
\hline \multirow{4}{*}{$\begin{array}{l}\text { How many hours do you spend using digital } \\
\text { devices? }\end{array}$} & $<2$ & \multicolumn{2}{|l|}{75} & 15.8 & \multirow[t]{4}{*}{$<0.001^{*}$} \\
\hline & $2-4$ & \multicolumn{2}{|l|}{163} & 34.3 & \\
\hline & $4-6$ & \multicolumn{2}{|l|}{129} & 27.2 & \\
\hline & $>6$ & \multicolumn{2}{|l|}{108} & 22.7 & \\
\hline \multirow[t]{3}{*}{ How many devices do you have? } & 1 & \multicolumn{2}{|l|}{204} & 42.9 & \multirow[t]{3}{*}{$<0.001 *$} \\
\hline & 2 & \multicolumn{2}{|l|}{169} & 35.6 & \\
\hline & $>2$ & \multicolumn{2}{|l|}{102} & 21.5 & \\
\hline \multirow{4}{*}{$\begin{array}{l}\text { Do you know the bad effects of overusing digital } \\
\text { devices? }\end{array}$} & Decreased visual acuity & \multicolumn{2}{|l|}{286} & 60.2 & \multirow[t]{4}{*}{$<0.001 *$} \\
\hline & Lack of concentration & \multicolumn{2}{|l|}{94} & 19.8 & \\
\hline & $\begin{array}{l}\text { Decreased scholar } \\
\text { performance }\end{array}$ & \multicolumn{2}{|l|}{57} & 12.0 & \\
\hline & None & \multicolumn{2}{|l|}{38} & 8.0 & \\
\hline \multirow{8}{*}{$\begin{array}{l}\text { What are the solutions to decrease the dangers of } \\
\text { overusing digital devices? }\end{array}$} & \multirow[t]{2}{*}{ Decrease hours of using } & No & 258 & 54.3 & \multirow[t]{2}{*}{0.066} \\
\hline & & Yes & 217 & 45.7 & \\
\hline & \multirow[t]{2}{*}{ Education of society } & No & 332 & 69.9 & \multirow[t]{2}{*}{$<0.001 *$} \\
\hline & & Yes & 143 & 30.1 & \\
\hline & \multirow[t]{2}{*}{ Scheduling hours } & No & 261 & 54.9 & \multirow[t]{2}{*}{$0.035^{*}$} \\
\hline & & Yes & 214 & 45.1 & \\
\hline & \multirow[t]{2}{*}{ Others } & No & 436 & 91.8 & \multirow[t]{2}{*}{$<0.001 *$} \\
\hline & & Yes & 39 & 8.2 & \\
\hline
\end{tabular}

\subsection{Predictors of visual and muscular complaints}

The logistic regression model identified gender as a significant predictor of complaints as women had a significantly higher likelihood of suffering from symptoms compared to men (OR: 2.8, 95\% CI: 1.6-4.8, p<0.001). Exposure to digital devices for more than 2 hours per day was associated with an increased risk of suffering from symptoms (OR: 2.9, 95\% CI: 1.4-6.3, p=0.006), when compared to those who used the devices for less than 2 hours per day (Table 4). 
Table 4. Predictors of visual and muscular symptoms.

\begin{tabular}{|c|c|c|c|c|c|}
\hline \multirow{2}{*}{\multicolumn{2}{|c|}{ Predictors }} & \multirow[t]{2}{*}{ p-value } & \multirow[t]{2}{*}{ OR } & \multicolumn{2}{|c|}{$95 \% \mathrm{CI}$} \\
\hline & & & & Lower & Upper \\
\hline \multicolumn{2}{|l|}{ Gender (Female) } & $<0.001^{*}$ & 2.753 & 1.566 & 4.839 \\
\hline \multirow[t]{4}{*}{ Duration of exposure (hour) } & $2-4$ & $0.006^{*}$ & 2.922 & 1.364 & 6.262 \\
\hline & $4-6$ & 0.179 & 1.650 & 0.794 & 3.426 \\
\hline & $>6$ & 0.053 & 2.191 & 0.989 & 4.857 \\
\hline & Total & $0.042 *$ & ------ & ------ & ------ \\
\hline
\end{tabular}

${ }^{*}$ CI: Confidence interval, OR: Odds ratio.

\section{Discussion}

The increased use of digital devices that has been witnessed in recent years has raised many concerns about the safety of these devices, particularly among the youth. Many studies have assessed health effects in adults or college students. However, only a few studies have evaluated their effects on children $(16,17)$; hence this study aimed to describe the pattern of use of digital devices, and to investigate the link between the use of these devices and the presence of visual symptoms among students of general education schools in the Western region of Saudi Arabia.

In this study, nearly half the respondents were males aged more than 19 years old and nearly a quarter of them aged 16-19 years old; most of whom attended secondary schools. This age group was found to be in line with other studies that investigated the use of SNSs among students (18). Interestingly, about one tenth of the respondents were young children aged 6-11 years, which is concerning given the expected accumulative exposure that they would experience by the time they graduated from school.

Based on our results, the most common complaints experienced after the use of digital devices were neck or shoulder pain, followed by headaches, eye dryness, and visual disturbances. Similar symptoms were previously reported by users of cell phones $(5-7)$ and computers $(16,19,20)$; and collectively have been labeled as "Computer vision syndrome" (21). This syndrome comprises many symptoms including headaches, eyestrain, blurred vision, dry eyes, irritated eyes, eye fatigue, light sensitivity, neck, back and shoulder pain, and double vision $(16,22)$. Other symptoms were reported in studies that evaluated the usage of SNSs including anxiety, social isolation, depression, nutritional disorders and deterioration of academic performance (23-26); these symptoms are mostly due to psychological dependence on SNSs and are not exactly related to the direct effect of digital devices. Many factors interact to give rise to the visual and muscular symptoms of this syndrome, mainly decreased blinking while focusing on the screen (27), and the uncomfortable posture maintained by users for long periods (28). However, Chu and colleagues (19) compared eye symptoms following reading from a computer monitor to reading a printed copy under similar viewing conditions and found that reported symptoms were significantly worse after computer use than after hard copy reading. This indicates that other factors might play a role in the etiology of this syndrome. Among these implicated factors are the emitted radiation (29), the brightness of the device's screen (particularly at night or with improper lighting conditions), and the thermal effect produced by the radio-frequency radiation on the eyes (30).

In the present study, the most commonly used digital devices were cellular phones or tablets; while electronic games, TVs, and computers/laptops were used by a much smaller percentage of the respondents. This is in accordance with the general observation that cellular phones or tablets are increasingly becoming the preferable tool to access the Internet, particularly SNSs (2). Also, cellular phones and tablets are attractive for young adults as a number of applications that promote communication (such as WhatsApp, Viber, etc...) and entertainment or even services (such as shopping, education) are available for these devices.

Approximately half of our respondents spent more than 4 hours daily using digital devices and had 2 or more devices. The high frequency of users of cellular phones or tablets in this study is expected, as most respondents were children and adolescents. Many students today are too much attached to their cell phone (particularly after the advent of smart phones); viewing it as an integral part of their personality (31). The prolonged use of devices, particularly cellular phones and tablets, is attributed again to the capabilities that enabled such devices to replace computers or laptops for many users. Cell phones, tablets, and other hand-held digital devices predispose the users to an increased risk of eyestrain due to their use with improper lighting and smaller font sizes (32). Nearly one third of our respondents were used to spending 2-4 hours on digital devices, which is in line with the study of Bijari et al. (24) who reported a mean duration using the computers, that ranged from 1.49 to 2.78 hours daily. The duration of 
using digital devices can also impact the prevalence and severity of visual and muscular symptoms, as they are more prevalent in persons exposed to monitors for more than 4 hours daily, based on previous data (20).

The most commonly reported health hazards by the respondents in our studied population were decreased visual acuity, lack of concentration and decreased academic performance. This may be attributed to an addictive-like phenomenon that attaches particularly the youth to their digital devices, even to the extent in which some young users consider cell phones as an extension of themselves or of their existence $(12,31)$.

In this study, most of the students agreed that decreasing the duration of usage and scheduling hours are the best solutions to decreasing the health hazards of digital devices. Studies showed that decreasing the duration of using computers ameliorates the symptoms of computer vision syndrome (5-7). Therefore, the user should take brief breaks from the computer every 20 minutes for 20 seconds or once per hour (33). Also, proper lighting conditions and correct, comfortable posture, particularly when sitting in front of desktop computers or laptops, can effectively decrease or delay the manifestations $(33,34)$.

Our results demonstrate that adolescents exposed to these devices for more than 2 hours a day are prone by about threefold to visual and muscular symptoms compared to those exposed for less than 2 hours a day. Additionally, females appeared to be more prone to symptoms; more analysis is needed to explain this gender differentiation. A probable explanation could be association to gender tendency, as it is the traditional attitude of women in Arab countries to stay indoors for longer durations than men. This attitude can result in women engaging more in the use of digital devices as a method of communication and entertainment, as a higher percentage of female students were found to use SNSs than males in a study by Erfanian et al. (18).

\section{Study Strengths and limitations}

A major point of strength is that this study is among the first papers to examine the pattern of digital device use among Saudi children and adolescents. However, the study was susceptible to many limitations including its cross sectional design. Furthermore, as it was conducted in the Western region of Saudi Arabia, it is assumed that these results can be generalized to other neighboring regions in Saudi Arabia. However, the results cannot be generalized to other countries due to cultural, technological, and economic variations between countries.

\section{Conclusions}

In conclusion, the use of digital devices was significantly more prevalent among youths aged above 19 years old attending secondary school. Visual and musculoskeletal symptoms that were related to the use of digital devices were experienced by a considerable significant proportion of respondents. Most respondents were aware that the use of digital devices for long hours is associated with visual and muscular complaints. Females and students exposed to computers for more than 2 hours a day are exceptionally more prone to such complaints. Decreasing the hours of usage is necessary to avoid digital device-related health risks. Health education is needed to teach the youth ergonomics as a preventive measure for this syndrome.

\section{Acknowledgments:}

We would like to acknowledge Dr. Ali M.A Alamri who assisted with data collection; and would like to thank all of the staff members of the schools that participated in this study for their cooperation and assistance.

\section{Conflict of Interest:}

There is no conflict of interest to be declared.

Authors' contributions:

All authors contributed to this project and article equally. All authors read and approved the final manuscript.

\section{References:}

1) AlOrainy A. Recent research on mobile phones effects. Proceedings of the International Conference on Non-Ionizing Radiation at UNITEN (ICNIR 2003) Available from: http://www.who.int/pehemf/meetings/archive/en/paper09alorainy.pdf

2) Boyd DM, Ellison NB. Social network sites: Definition, history, and scholarship. Journal of computer mediated Communication. 2007; 13(1): 210-30. doi: 10.1111/j.1083-6101.2007.00393.x. 
3) Pempek TA, Yermolayeva YA, Calvert SL. College students' social networking experiences on Facebook. Journal of applied developmental psychology. 2009; 30(3): 227-38. doi: 10.1016/j.appdev.2008.12.010.

4) Farahani HA, Kazemi Z, Aghamohamadi S, Bakhtiarvand F, Ansari M. Examining mental health indices in students using Facebook in Iran. Procedia-Social and Behavioral Sciences. 2011; 28: 811-4. doi: 10.1016/j.sbspro.2011.11.148.

5) Balik HH, Turgut-Balik D, Balikci K, Ozcan IC. Some ocular symptoms and sensations experienced by long term users of mobile phones. Pathologie-biologie. 2005; 53(2): 88-91. doi: 10.1016/j.patbio.2004.03.012. PMID: 15708652.

6) Meo SA, Al-Drees AM. Mobile phone related-hazards and subjective hearing and vision symptoms in the Saudi population. International journal of occupational medicine and environmental health. $2005 ; 18(1)$ : 53-7. PMID: 16052891.

7) Oftedal G, Wilen J, Sandstrom M, Mild KH. Symptoms experienced in connection with mobile phone use. Occup Med (Lond). 2000; 50(4): 237-45. doi: 10.1093/occmed/50.4.237. PMID: 10912374.

8) Kramarenko AV, Tan U. Effects of high-frequency electromagnetic fields on human EEG: a brain mapping study. International Journal of Neuroscience. 2003; 113(7): 1007-19. doi: 10.1080/00207450390220330. PMID: 12881192.

9) Trueman G, Tang L, Abdel-Rahman U, Abdel-Rahman W, Ong K, Cosic I. Human brain wave activity during exposure to radiofrequency field emissions from mobile phones. Australasian Physics \& Engineering Sciences in Medicine. 2003; 26(4):162-7. PMID: 14995060.

10) Lepp A, Barkley JE, Karpinski AC. The relationship between cell phone use and academic performance in a sample of US college students. Sage Open. 2015; 5(1). doi: 10.1177/2158244015573169.

11) Lee H, Kim MS, Son HK, Ahn S, Kim JS, Kim YH. Discriminating power of socio-demographic and psychological variables on addictive use of cellular phones among middle school students. Journal of Korean Academy of Nursing. 2007; 37(6): 957-65. PMID: 17992068.

12) Takao $M$, Takahashi $S$, Kitamura $M$. Addictive personality and problematic mobile phone use. CyberPsychology \& Behavior. 2009; 12(5): 501-7. doi: 10.1089/cpb.2009.0022. PMID: 19817562.

13) Hardell L, Mild KH, Carlberg M, Söderqvist F. Tumour risk associated with use of cellular telephones or cordless desktop telephones. World Journal of Surgical Oncology. 2006; 4(1): 74. doi: 10.1186/1477-78194-74. PMID: 17034627, PMCID: PMC1621063.

14) Krishnan S, Zakaria A, Khalil F, Jofree S. The Effect of Electronic Device on Human Health. Management. 2017; 7(1): 40-3. doi: 10.5923/j.mm.20170701.05.

15) Charan J, Biswas T. How to Calculate Sample Size for Different Study Designs in Medical Research? Indian Journal of Psychological Medicine. 2013; 35(2): 121-6. doi: 10.4103/0253-7176.116232. PMID: 24049221, PMCID: PMC3775042.

16) Kozeis N. Impact of computer use on children's vision. Hippokratia. 2009;13(4): 230. PMID: 20011087, PMCID: PMC2776336.

17) Christ A, Gosselin M-C, Christopoulou M, Kühn S, Kuster N. Age-dependent tissue-specific exposure of cell phone users. Physics in medicine and biology. 2010; 55(7): 1767-83. doi: 10.1088/00319155/55/7/001. PMID: 20208098.

18) Erfanian M, Javadinia SA, Abedini M, Bijari B. Iranian students and social networking sites: Prevalence and pattern of usage. Procedia-Social and Behavioral Sciences. 2013; 83: 44-6. doi: 10.1016/j.sbspro.2013.06.009.

19) Chu C, Rosenfield M, Portello JK, Benzoni JA, Collier JD. A comparison of symptoms after viewing text on a computer screen and hardcopy. Ophthalmic and Physiological Optics. 2011; 31(1): 29-32. PMID: 21197801.

20) Rossignol AM, Morse EP, Summers VM, Pagnotto LD. Video display terminal use and reported health symptoms among Massachusetts clerical workers. Journal of Occupational and Environmental Medicine. 1987; 29(2): 112-8. PMID: 3819890.

21) Grant AH. The computer user syndrome. Journal of the American Optometric Association. 1987; 58(11): 892-901. PMID: 3693780.

22) Murata K, Araki S, Yokoyama K, Yamashita K, Okumatsu T, Sakou S. Accumulation of VDT workrelated visual fatigue assessed by visual evoked potential, near point distance and critical flicker fusion. Industrial health. 1996; 34(2): 61-9. PMID: 8857276.

23) Kirschner PA, Karpinski AC. Facebook ${ }^{\circledR}$ and academic performance. Computers in human behavior. 2010; 26(6): 1237-45. doi: 10.1016/j.chb.2010.03.024. 
24) Bijari B, Javadinia SA, Erfanian M, Abedini M, Abassi A. The impact of virtual social networks on students' academic achievement in Birjand University of Medical Sciences in East Iran. Procedia-Social and Behavioral Sciences. 2013; 83: 103-6. doi: 10.1016/j.sbspro.2013.06.020.

25) Beard KW. Internet addiction: Current status and implications for employees. Journal of Employment Counseling. 2002; 39(1): 2-11. doi: 10.1002/j.2161-1920.2002.tb00503.x.

26) Young KS. Internet addiction: The emergence of a new clinical disorder. Cyberpsychology \& behavior. 1998; 1(3): 237-44. doi: 10.1089/cpb.1998.1.237.

27) Helland M, Horgen G, Kvikstad TM, Aarås A. Do Background Luminance Levels or Character Size Effect the Eye Blink Rate During Visual Display Unit (VDU) Work-Comparing Young Adults with Presbyopes? International Conference on Ergonomics and Health Aspects of Work with Computers; 2007: Springer.

28) Tribley J, McClain S, Karbasi A, Kaldenberg J. Tips for computer vision syndrome relief and prevention. Work. 2011; 39(1): 85-7. doi: 10.3233/WOR-2011-1183. PMID: 21673432.

29) Nakamura H, Matsuzaki I, Hatta K, Nobukuni Y, Kambayashi Y, Ogino K. Nonthermal effects of mobilephone frequency microwaves on uteroplacental functions in pregnant rats. Reproductive toxicology (Elmsford, NY). 2003; 17(3): 321-6. doi: 10.1016/S0890-6238(03)00010-8. PMID: 12759101.

30) Chen H-Y, Yang H-P. Temperature increase in human heads due to different models of cellular phones. Electromagnetics. 2006; 26(6): 439-59. doi: 10.1080/02726340600837891.

31) Belk RW. Possessions and the extended self. Journal of consumer research. 1988; 15(2): 139-68. doi: $10.1086 / 209154$.

32) Gowrisankaran S, Sheedy JE. Computer vision syndrome: A review. Work. 2015; 52(2): 303-14. doi: 10.3233/WOR-152162. PMID: 26519133.

33) Verma SB, Gurwood AS. Eye strain (Asthenopia). In: Levy BS, Gregory RW, Rest KM, Weeks JL, editors. Preventing occupational disease and injury. second ed. Washington, DC: American Public Health Association; 2005. p. 200 -1. PMID: 16250477.

34) González ST, Ortiz-Hernández L, Martínez-Alcántara S, Méndez-Ramírez I. Health hazards associated with the use of video display terminals. Salud Pública de México. 2003; 45(3): 171-80. 